\title{
We say farewell to Dr. Hideo Toraya
}

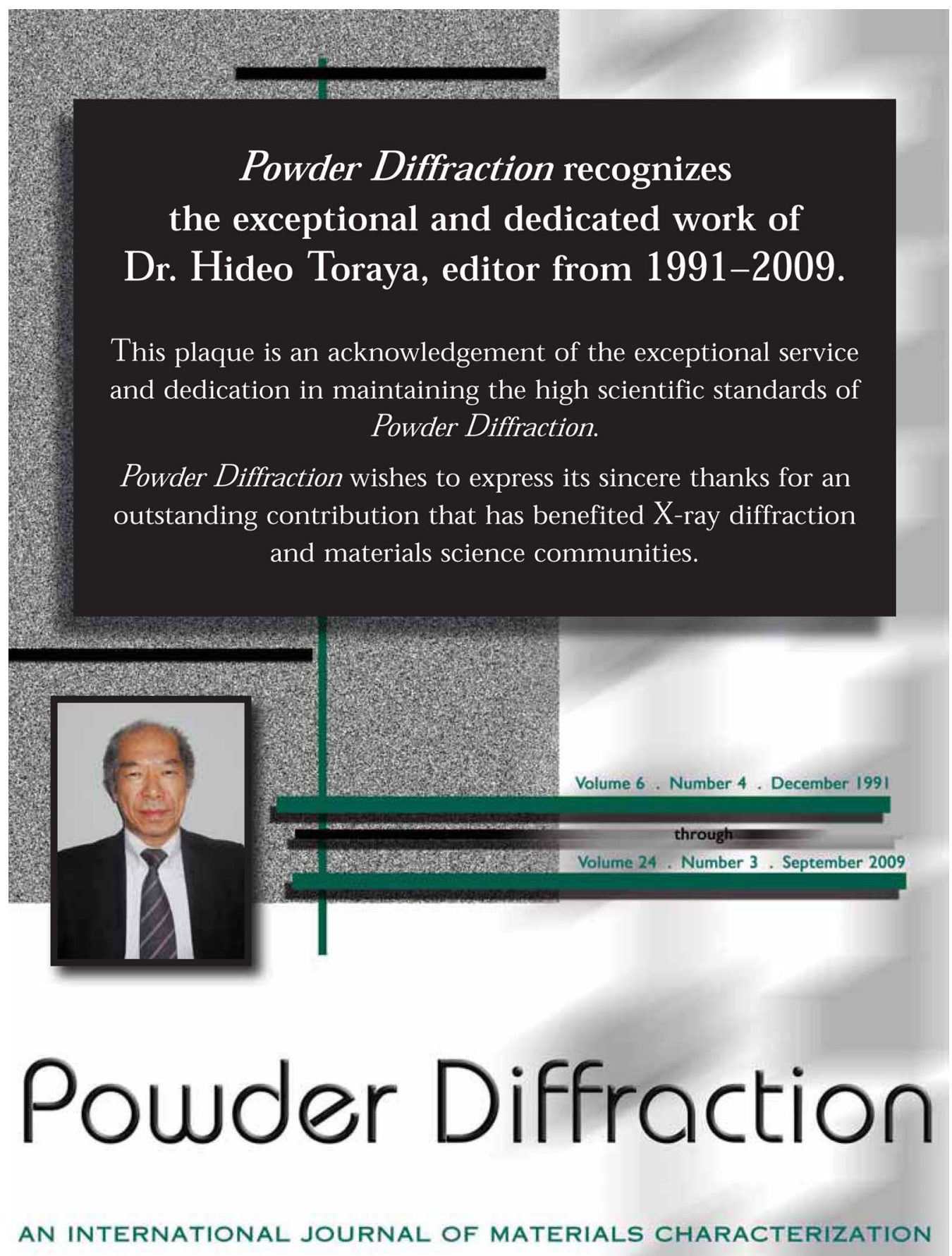

Last October, Dr. Hideo Toraya informed Powder Diffraction that he will be stepping down as editor of the journal because of his new responsibilities at Rigaku Corporation. We have no choice but to reluctantly accept his resignation as editor for Powder Diffraction.

Dr. Toraya became an editor in 1991. Dr. Toraya has done an excellent job on editing and improving the many papers submitted from around the world and for his impor- tant suggestions on improving the editorial process for Powder Diffraction.

In addition to his editorial work for Powder Diffraction, Dr. Toraya has been very active in the powder-diffraction and crystallography communities. He served as an ICDD Asia regional representative (1993-1998) and became a regional co-chair (1998-2002). He was a member of the Commission on Powder Diffraction of the International Union of Crystal- 
lography (1993-1999) and was also an executive member of the Asian Crystallography Association (1996-2002). In recognizing Dr. Toraya's valuable contributions to the activities of the powder-diffraction community in general and ICDD in particular, he was awarded an ICDD Fellowship by the ICDD Board of Directors in 2001.

Dr. Toraya has an outstanding professional career. He obtained his Doctor of Science degree from Tokyo Institute of Technology in 1980 and became a research associate there from 1981 to 1984 . He then joined Nagoya Institute of Technology in 1984 and became a full professor in 1994. He retired from Nagoya Institute of Technology and joined Rigaku Corporation in 2003. Dr. Toraya is now a vice president and director of the X-ray research laboratory as well as the head of the applications laboratory at Rigaku.

Dr. Toraya is a renowned scientist for his outstanding contributions in the field of powder diffraction and materials science. He is the author of the popular computer programs PRO-FIT, WPPF, and PFLS. He is also known for his innovative development of a powder diffractometer equipped with multiple detectors in 1995. The diffractometer is currently used for high-speed powder-diffraction measurements in the Photo Factory of KEK at Tsukuba, Japan. Two of the awards Dr. Toraya received were on his contributions to the study of X-ray powder-diffraction profiles from Crystallography Society of Japan in 1991 and to the accurate crystal-structure analysis of ceramic materials using synchrotron radiation and laboratory X-ray sources from Ceramic Society of Japan in 2001.

From 1989 to 1990, Dr. Toraya was on sabbatical leave from Nagoya Institute of Technology and came to IBM Almaden Research Center in San Jose, California, working as a visiting scientist with the late Dr. William Parrish. During his stay at IBM, Dr. Toraya and I had many opportunities to interact and discuss our work on powder-diffraction techniques and applications. I have found that he is an intelligent and talented scientist as well as a kind and devoted family man.

It is regrettable that he has to give up his editorial position with Powder Diffraction. However, we are delighted to learn that he will continue to participate in other powderdiffraction activities including serving as a member of the Organizing Committee of the 9th Pharmaceutical Powder X-ray Diffraction Symposium (PPXRD-9) in February 2010 at Hilton Head Island, South Carolina.

To express our sincere thanks for his outstanding contributions that have benefited the powder-diffraction and materials science communities, a citation plaque is presented to Dr. Toraya by this journal to recognize his exceptional and dedicated work as editor from 1991 to 2009 (see the attached photo of the plaque). We wish him all the best.

Ting C. Huang Editor-in-Chief 